\title{
THE WALLDIUS HINGE ARTHROPLASTY
}

\author{
Hugh Phillips, London, and J. G. Taylor, Norwich, England
}

From the Department of Orthopaedic Surgery and Rheumatology, Norfolk and Norwich Hospital, Norwich

Eighty-three Walldius arthroplasties, performed by one surgeon as a salvage operation on the knee joint between 1966 and 1972, were independently reviewed. The fifty-seven living patients with sixty-seven arthroplasties were interviewed and examined and the clinical records of the deceased patients were inspected. Sixty-seven arthroplasties (81 per cent) were successful and sixteen failed (19 per cent). Acrylic cement was used to secure the prosthesis on eight occasions only. There were two primary infections $(2 \cdot 4$ per cent $)$ and two delayed (2.4 per cent). Major loosening occurred in three arthroplasties (3.6 per cent). Minor loosening was compatible with a good result. Arthrodesis was successful on the two occasions on which it became necessary to remove the implant. There were no disasters. On the basis of these results it is considered that the Walldius arthroplasty can justifiably be offered as an alternative to primary arthrodesis of the knee.

Replacement arthroplasty is now becoming accepted as a salvage operation for the knee in the advanced stage of rheumatoid arthritis. The indications for the operation are severe pain and instability of disabling degree in polyarthritic patients. Destruction of the joint should be too advanced for any hope of a good result from synovectomy-débridement or double osteotomy.

Non-linked metal to plastic prostheses represent the current trend in design. These offer theoretical advantages over the hinge and interposition arthroplasties which preceded them. Results of these new operations have been reported (Gunston 1971; Freeman and Swanson 1972). It seems appropriate to present as a basis for comparison a recent assessment of a series of cases in which a simple hinge arthroplasty (Walldius 1957) was used.

Blundell Jones (1968) reported the results of fortyfive Walldius replacements performed by surgeons at Exeter, and this paper reports experience in the use of this prosthesis during the years 1966 to 1972 at Norwich. All patients were operated upon by one surgeon (J. G. T.) and the review has been carried out independently by the other (H. P.).

\section{CLINICAL MATERIAL}

Eighty-three Walldius arthroplasties have been performed in seventy patients. Thirteen, with sixteen arthroplasties, have subsequently died from causes unrelated to the operation. The fifty-seven surviving patients with sixtyseven arthroplasties have been interviewed and examined for the purpose of this investigation, and the clinical records of the deceased patients have been scrutinised.

The ages of the reviewed and deceased patients at the time of operation are shown in the histogram (Fig. 1). The mean age was sixty-one years and the age scatter was from eighteen to eighty years. There were sixty-five

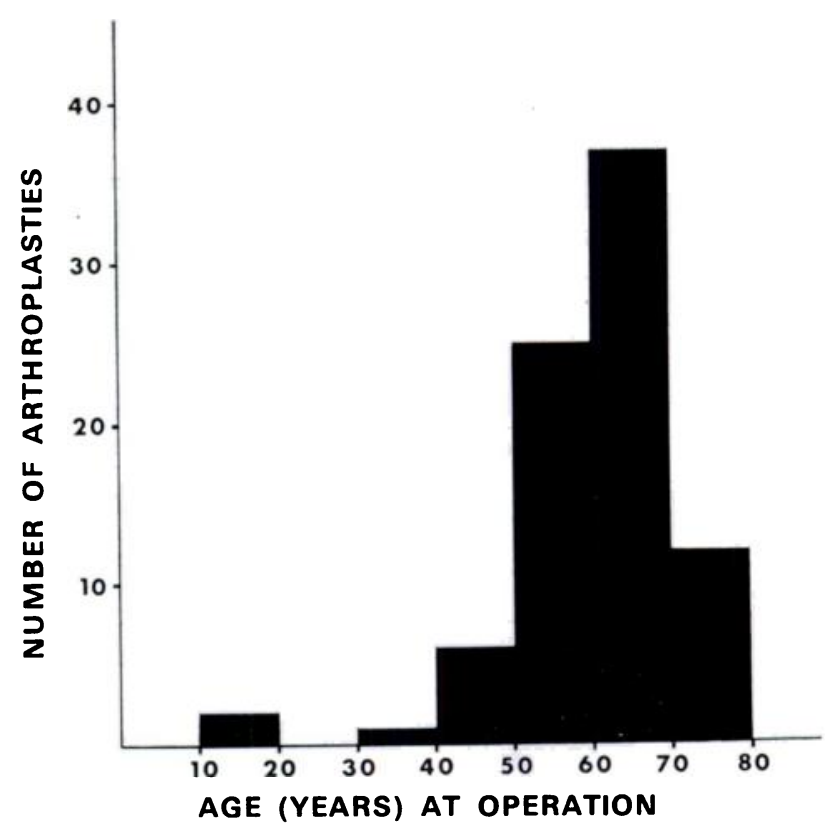

Fig. 1

Histogram of age at operation (eighty-three arthroplasties).

women and five men. Sixty-seven patients had classical rheumatoid arthritis and there were only three with osteoarthritis. The duration of follow-up in the sixty-seven reviewed knees is summarised in Figure 2 . It varied between six and eighty-one months, with a mean of forty-one months.

The indication for operation in the eighty-three knees was pain alone in twenty-nine and pain with instability in fifty-four. Lateral deformity of more than 10 degrees on standing was present in sixty knees. This deformity was usually valgus. In fifty-six knees there was a flexion deformity of between 5 and 30 degrees. Patients with flexion deformity greater than 30 degrees were admitted to hospital for serial splintage until correction was achieved. 


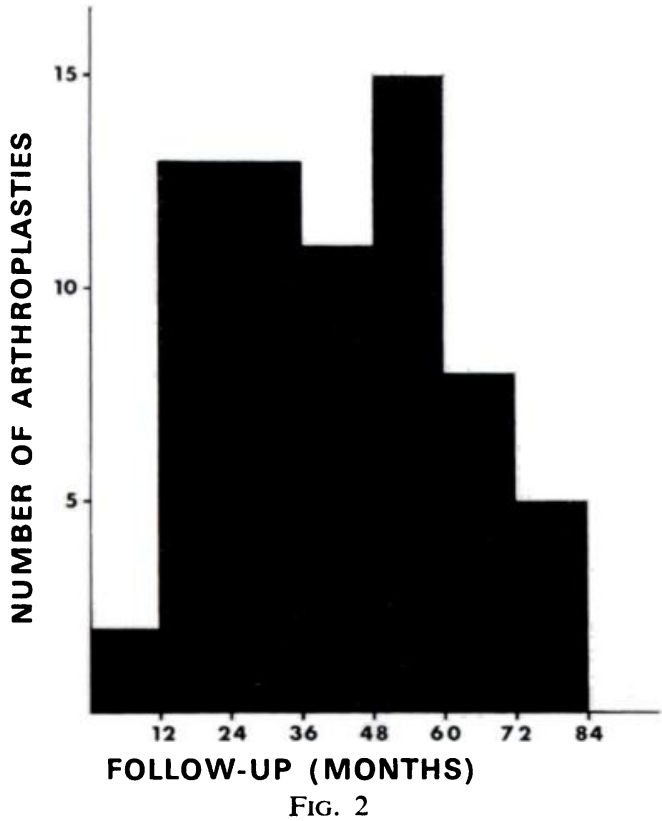

Duration of follow-up of sixty-seven arthroplasties.

\section{THE OPERATION}

A standard Vitallium Walldius prosthesis with tencentimetre stems was inserted on each occasion. In all operations the anterior transverse approach (Walldius 1957 ) with retention of the patella was used. A pneumatic tourniquet was used except in patients with evidence of peripheral arterial or venous disease.

Fixation with acrylic cement was seldom employed; it was used for one component in five arthroplasties and for both components in three. The indication for bone fixative was marked slackness of either stem at the time of insertion. Cancellous grafts taken from the resected bone were used to fill defects or cysts in the tibia or femur. Cancellous wedges provided, when necessary, accurate seating of the components on the recipient bone surfaces. Suction drainage was routine.

After operation the limb was immobilised in a padded plaster-of-Paris cylinder for two weeks. The wound was then inspected and a new cylinder applied in which weight-bearing was encouraged for a further two weeks. This routine period of immobilisation was extended only in the event of delayed wound healing. All patients received systemic antibiotic therapy before and for fourteen days after operation. Cloxacillin was the antibiotic of choice unless there was hypersensitivity to penicillin, in which case Lincomycin was used.

\section{RESULTS}

The results have been classified as successful or failed. An arthroplasty was considered successful if all of the following criteria were fulfilled: 1) freedom from pain or only very slight pain; 2) a stable joint with corrected deformity; 3) at least 60 degrees of flexion; 4) absence of a continuing major complication; and 5) the patient should be pleased.

On these criteria, there were sixty-seven successful and sixteen failed arthroplasties in the whole series of eighty-three. The success rates in the whole series, including deceased patients, and in the personally reviewed surviving patients were identical. Table I summarises these results.

TABLE I

Summary of Results (EIghty-three Arthroplasties)

\begin{tabular}{lcccc}
\hline & Success & Failure & Total & $\begin{array}{c}\text { Percentage } \\
\text { failure }\end{array}$ \\
\hline $\begin{array}{l}\text { Reviewed patients } \\
\text { Deceased patients } \\
\text { Total }\end{array}$ & 54 & 13 & 67 & 19 \\
\cline { 2 - 3 } & 67 & 3 & 16 & 19 \\
\hline
\end{tabular}

Successful arthroplasties-There were fifty-four successful arthroplasties in surviving patients. Thirty knees were completely pain-free; twenty-four gave slight pain or discomfort, which was not disabling and did not require analgesia. In twelve of these twenty-four knees an aching feeling was noticed when the patient began walking after a period of rest, or when sitting after a period of walking. These twelve prostheses were clinically loose within bone In the group of deceased patients who had had successful arthroplasties, seven had been totally pain-free and six had had mild pain. These findings are summarised in Table II

The range of flexion attained in the sixty-seven successful arthroplasties varied between 60 and 90 degrees. Thirty knees had 90 degrees of flexion and the mean flexion was 82 degrees (Fig. 3).

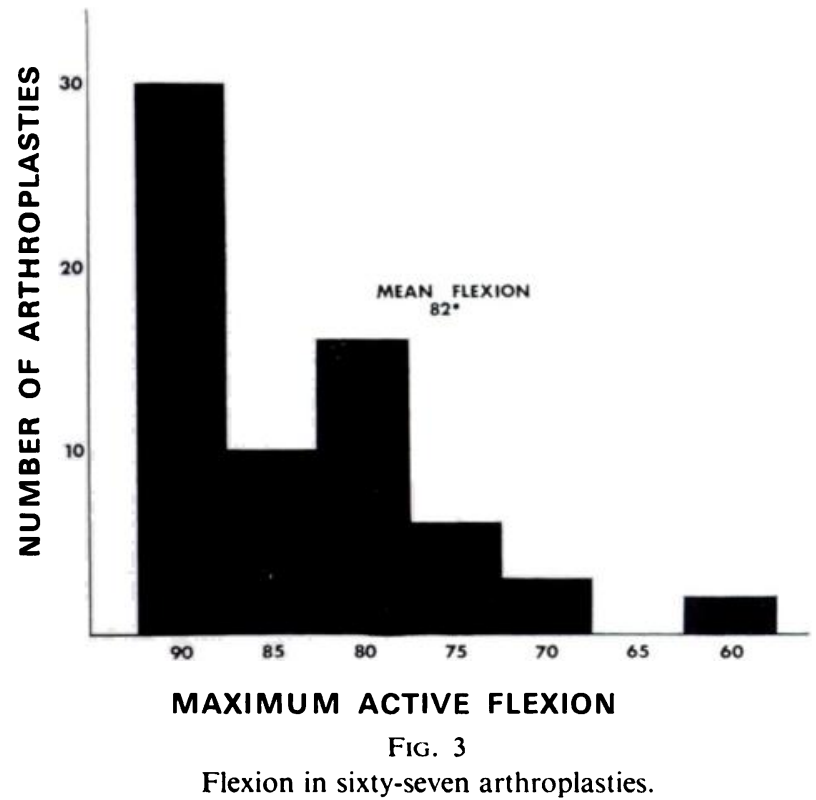

THE JOURNAL OF BONE AND JOINT SURGERY 
All the successful arthroplasties were subjectively stable. Forty-one of the fifty-four implants in successful cases reviewed were, however, detectably loose as shown by a slight rock of the prosthesis on lateral or rotational straining.

Failed arthroplasties-The failure rate both in the reviewed patients and in the series as a whole was 19 per cent. Table III summarises the sixteen failed arthroplasties.

TABLE II

Pain Relief in Sixty-Seven Arthroplasties

\begin{tabular}{|c|c|c|}
\hline & Pain-free & Minimal pain \\
\hline Reviewed & 30 & 24 \\
\hline Deceased & 7 & 6 \\
\hline Total & 37 & 30 \\
\hline
\end{tabular}

Major sepsis occurred in four arthroplasties, a rate of 4.8 per cent. Two infections were primary and two delayed; all led to failure.

One primary infection necessitated removal of the prosthesis and arthrodesis; the other was overcome with lavage, irrigation and antibiotics, giving a knee without

TABLE III

The FaILED ARTHROPLASTIES

\begin{tabular}{|c|c|c|}
\hline Reason for failure & Treatment & Outcome \\
\hline \multirow{2}{*}{ Primary sepsis (2) } & Arthrodesis & Sound fusion \\
\hline & $\begin{array}{l}\text { Lavage, irrigation, } \\
\text { antibiotics }\end{array}$ & Pain-free, 30 flexion \\
\hline \multirow{2}{*}{ Delayed sepsis (2) } & $\begin{array}{l}\text { Lavage, irrigation, } \\
\text { antibiotics }\end{array}$ & Painful, 90 flexion \\
\hline & $\begin{array}{l}\text { Lavage, irrigation, } \\
\text { antibiotics }\end{array}$ & Painful, 60 flexion \\
\hline \multirow{2}{*}{ Major loosening (2) } & Arthrodesis & Sound fusion \\
\hline & Awaiting revision & Painful \\
\hline $\begin{array}{l}\text { Rupture of the } \\
\text { extensor mechanism (1) }\end{array}$ & Repaired & Painful $<60$ flexion \\
\hline \multirow{2}{*}{ Low grade synovitis (2) } & $\begin{array}{l}\text { Anti-inflammatory } \\
\text { drugs }\end{array}$ & Painful \\
\hline & $\begin{array}{l}\text { Anti-inflammatory } \\
\text { drugs }\end{array}$ & Painful \\
\hline Inadequate flexion (7) & Nil effective & All $<60^{\circ}$ flexion \\
\hline
\end{tabular}

pain but with only 30 degrees of flexion. The delayed infections occurred at twenty-seven and thirty-three months from the time of operation. The offending organisms were cultured and proved to be a bacillus Proteus in one case and a penicillin-sensitive staphylococcus in the other. Both patients were treated with irrigation and the appropriate antibiotic. The infections appear to have resolved but both of these knees remain painful.
Loosening of the prosthesis within the bone, sufficient to produce severe pain, occurred on three occasions. One patient, now deceased, required arthrodesis eight months after arthroplasty because both stems were loose in soft eroded bone. One markedly loose prosthesis was reinserted after two and a half years. Bone fixative was used to secure the prosthesis and the outcome has been entirely satisfactory. This arthroplasty has therefore been included in the successful group. A third patient is awaiting revision of an arthroplasty in which the prosthesis is very loose.

Rupture of the quadriceps mechanism at the level of the patellar ligament occurred in one patient, two years after operation. This required operative repair, with lengthening of the rectus femoris. This arthroplasty is now considered a failure because of stiffness and pain.

There have been two further arthroplasties with pain. In both patients there has been active rheumatoid synovitis in other joints and it seems probable that there is a similar synovitis around the replaced joints.

TABLE IV

Other Complications in Eighty-three Arthroplasties

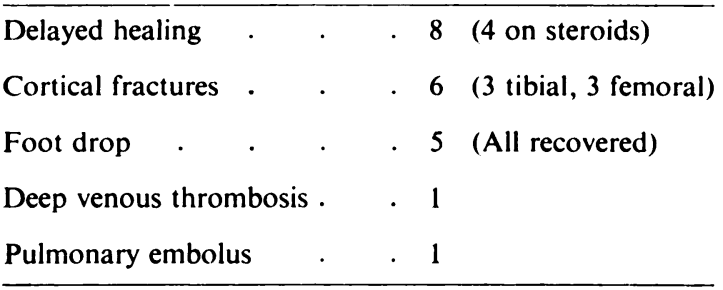

Seven knees had less than 60 degrees of active flexion. In four, this was present from the time of operation. One patient suffering from juvenile rheumatoid arthritis had bilateral Walldius arthroplasties at the age of eighteen years. During the five years since operation there has been loss of knee flexion which is now limited to 35 degrees on one side and 40 degrees on the other. Although her arthroplasties are classified as failures, the patient is pleased. Since operation she has married and now manages her own home and infant. In one octogenarian, sinking of the prosthesis into the cancellous bone has caused limitation of flexion to 30 degrees.

Other complications of the operation are summarised in Table IV; they have not prejudiced the result of operation. Foot drop occurred in five patients in whom gross valgus deformity had to be corrected. Full recovery occurred in every case. Delayed wound healing occurred on eight occasions. Four of these patients were being treated with steroids. A skin graft was needed on one occasion and the outcome was successful. Minor cortical fractures have occurred six times, but have not predisposed to pain or loosening of the prosthesis. There was one deep venous thrombosis, and one patient had a nonfatal pulmonary embolus.

The walking ability of the surviving patients was assessed and compared with the state before operation. 
Forty of the fifty-seven surviving patients had improved mobility following operation and in twelve there was no change. Five patients, in all of whom there had been deterioration in other joints, were less mobile. Seventeen required no aids at all and twenty-three had progressed to a simpler type of walking aid. Seven of the nine patients who had led a chair-bound existence before operation were able to walk at the time of review.

\section{DISCUSSION}

Classification of the results of knee arthroplasty in rheumatoid patients into several categories is unhelpful and may be misleading. The opinion of the patient is a useful indication of success or failure. Provided the patient is pleased and the arthroplasty meets the objective criteria referred to above, the operation is successful.

The two absolute requirements of an arthroplasty of the knee are relief of pain and stability. In addition, the operation must give flexion adequate for the needs of the individual patient. The range of movement compatible with success is variable, depending upon the condition of the hips, contralateral limb and the function of upper limbs.

An inherent defect of the Walldius implant is its inability to flex beyond 90 degrees. Some patients experience difficulty in rising from the seated position as a result of this limitation. The use of available upper limb function, selection of a chair of suitable height and sometimes the employment of an ejector seat have enabled all but five of the patients reviewed to get up from a seated position without assistance. We consider that flexion of less than 60 degrees confers little advantage over an arthrodesis and arthroplasties with this small range have been considered failures. The adoption of a minimum flexion requirement for a successful result has, however, meant that three arthroplasties which have entirely pleased the recipients have been classified as failures.

Hinge prostheses lock in full extension and allow no rotation. These features predispose to loosening. Forty- eight of the reviewed arthroplasties of this series ( 72 per cent) were detectably loose on clinical examination. Minor loosening is, however, compatible with a good result for in just over three-quarters of the successful arthroplasties the prosthesis was clinically slack in the bone. Gross loosening giving rise to severe pain occurred in only three cases ( 3.6 per cent), a figure which compares favourably with symptomatic loosening of the components of total hip replacement (Theodorou and Dandy 1973). Acrylic cement does not prevent loosening of a hinge prosthesis, for this was detectable in all three of the arthroplasties in which both components had been cemented in.

The achievement of a mobile knee should not subject the patient to operative risks unduly greater than those of arthrodesis. Furthermore, the arthroplasty should not preclude arthrodesis in the event of failure.

Major sepsis in the prosthetic knee joint is a hazard which must not create permanent wound breakdown, make arthrodesis impossible and necessitate amputation, nor need it make removal of the joint mandatory. Three of the four infections in this series were overcome by lavage, continuous irrigation with the appropriate antibiotic, and systemic antibiotics, the joint being retained. Although residual pain or lack of flexion required these to be classified as failures, arthrodesis could be undertaken if disability warranted, as in the fourth case. We believe that Walldius's transverse approach with retention of the patella, minimal use of acrylic cement, and discrimination in the use of the tourniquet, are relevant factors in a low sepsis rate and avoidance of disaster.

The Walldius hinge arthroplasty without cement fixation is an operation which need not jeopardise the limb. It can justifiably be offered as an alternative to arthrodesis for the advanced rheumatoid knee. It may well be that the metal to plastic non-linked prostheses will give results superior to the Walldius. There may remain, however, some knees where instability and destruction of one or other tibial condyles is too severe for a non-linked prosthesis to give a satisfactory result, when the hinge prosthesis will still be indicated.

We wish to thank Dr N. Cardoe and Dr W. G. Wenley who referred the patients for surgery. Our thanks are also due to Miss Jane Brighton who prepared the typescript.

\section{REFERENCES}

Freeman, M. A. R., and Swanson, S. A. V. (1972) Total prosthetic replacement of the knee. Journal of Bone and Joint Surgery, 54-B, 170-171. Gunston, F. H. (1971) Polycentric knee arthroplasty. Journal of Bone and Joint Surgery, 53-B, 272-277.

Jones, G. B. (1968) Arthroplasty of the knee by the Walldius prosthesis. Journal of Bone and Joint Surgery, 50-B, 505-510. Theodorou, B., and Dandy, D. J. (1973) Personal communication.

Walldius, B. (1957) Arthroplasty of the knee using an endoprosthesis. Acta orthopaedica Scandinavica, Supplementum 24. 